\title{
Reconciling tree-ring sampling with conservation
}

\author{
R. A. MORGAN, J. HILLAM, J. M. COLES \& S. McGRAIL
}

\begin{abstract}
Fennifer Hillam and Ruth Morgan run the DoE-financed Dendrochronology Laboratory in the Prehistory and Archaeology Department of the University of Sheffield. The laboratory handles most of the wood excavated in England, of all periods. Professor Fohn Coles, Department of Archaeology, University of Cambridge, is director of the Somerset Levels Project. Sean McGrail is Chief Archaeologist at the National Maritime Museum at Greenwich, and specializes in the study of prehistoric craft and logboats. The authors here set out to remove some misconceptions in the field of dendrochronology. They explain how sampling need not destroy timbers required for conservation, and how the results of such analyses may be vital to tree-ring research and archaeological dating.
\end{abstract}

A recent article (Lawler, I980) mentioned a common misunderstanding in archaeological circles which this note attempts to correct: 'The (Runnymede) piles selected will be subjected to destructive testing (i.e. dendrochronology) to gain information concerning growth patterns, habitat and treefelling patterns...' In fact, dendrochronology is not a destructive dating method in the sense of radiocarbon analysis, where the wood sample is burnt up and completely lost. Instead, the section removed for tree-ring analysis remains undamaged and can easily be restored to the beam or pile for conservation without any detriment to the timber's display potential.

Alternatively, from a museum angle, timbers could be displayed with sample holes or missing sections, creating a valuable opportunity to explain to the general public how various research techniques can increase our knowledge of the past. We here discuss in detail how dendrochronology works, emphasize the importance of allowing adequate sampling, and suggest how this can be combined with conservation programs.

\section{THE NEED FOR EXTENSIVE SAMPLING}

A common misconception among archaeologists is that a sample from one oak timber per structure or feature is sufficient to produce a reliable tree-ring date. While this is occasionally true, more often than not the single sample has to be rejected because it contains less than $5^{\circ}$ growth rings, and thus its pattern of wide and narrow annual rings may not be unique (Huber \& Giertz, I970). Even with more than 50 rings, a single tree-ring curve cannot always be synchronized with a dated chronology because the general climatic signals, which govern the widths of the rings, are being obscured by local growth conditions. However, if most or all of the timbers within a structure are sampled, some at least are likely to have originated in mature oaks with more than 50 rings, and the possibilities of producing a site mean curve will be enhanced through the matching together of several individual curves. Because the site mean curve is an average growth pattern, much of the 'background noise' due to local growth conditions has been removed, leaving the vital climatic signals. It is then more likely to correspond with a reference chronology (one which is absolutely dated), so producing accurate dates for the felling of trees used in the feature.

The felling date is also more accurately estimated when the positions of several end years are available, i.e. the date of the final ring which can be measured on each timber (Hollstein, 1965). Where only one or two timbers are sampled, the results might be difficult to interpret and thus of far less value than results from an extensively sampled site (FIG. I).

The advantages of extensive sampling for treering analysis have been amply demonstrated by work at many sites outside Britain, such as Dublin (Baillie, 1977), Dorestad (Eckstein et al., 1975) and Hedeby (Eckstein, 1978). At Hedeby, over 4,000 

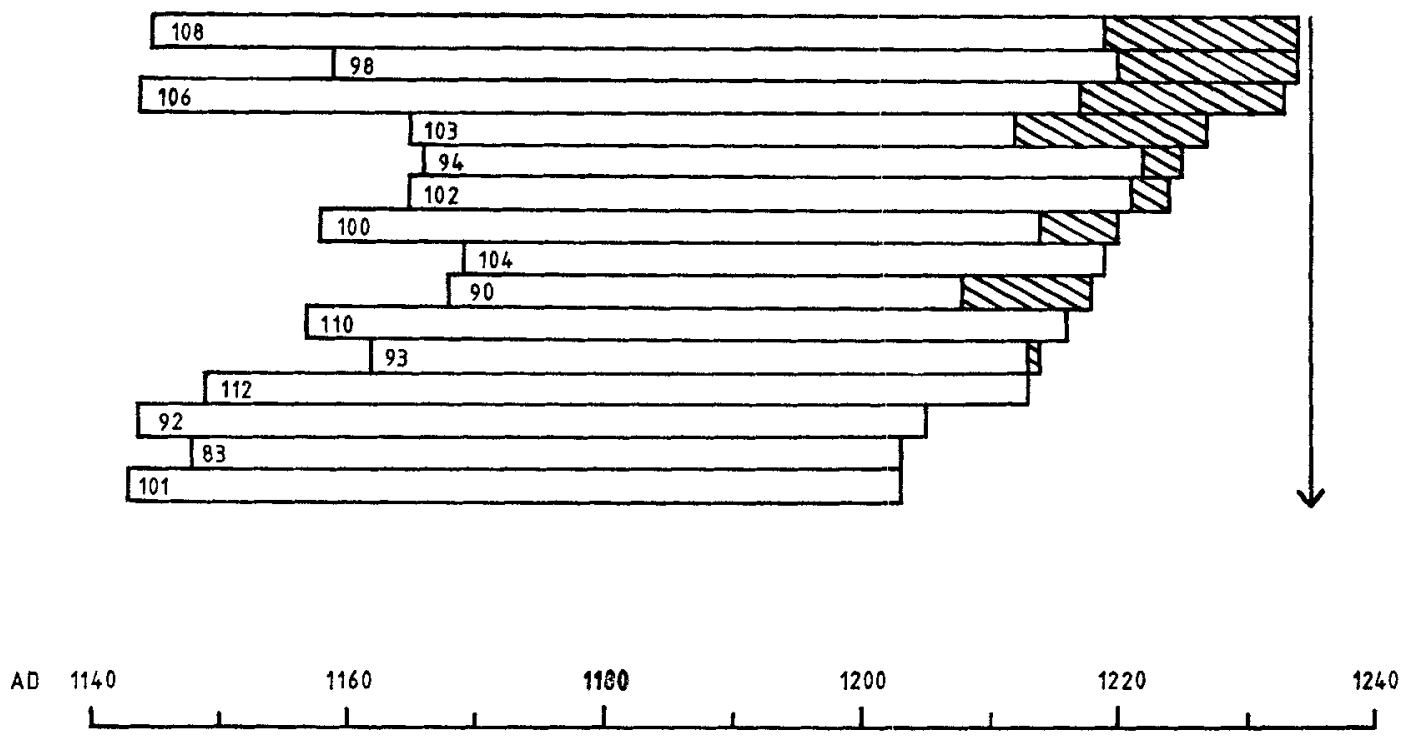

F123

\begin{tabular}{|l|l|l|}
\hline 36 & 1 \\
\hline 35 & & \\
\hline
\end{tabular}

7868 53

40

Fig. I. Block diagrams illustrating the contrast between the value of information gained from an extensively sampled site and one producing only one or two samples per feature. Each block = the years spanned by an individual timber; hatching = sapwood, and the vertical arrow = the estimated terminus post quem felling date. 15 timbers from the Mermaid Theatre site in London (above) enable an accurate felling date to be determined from their combined sapwood boundaries. From Odell, Beds. (below), a series of Saxon wells, only one or two timbers per context could be sampled, all lacking sapwood. The results are impossible to interpret satisfactorily and could be considerably altered by the addition of more samples. For example, FI23 may date to c. AD 530 and have been repaired c. 60o, or may have been built at the late date using some older wood. F868 could date to c. 530 or to c. 640. The temporal relationship between the wells cannot be determined. (Drawn by $\mathcal{F}$. Hillam) 
samples gave minute stratigraphical detail; at Schleswig, between 9 and 90 timbers per structure were examined (Eckstein, 1980). Dendrochronological work such as this is revolutionizing early medieval and later archaeology in Europe since, for the first time, structures can be dated with absolute reliability to a single year and sometimes even to the season.

In Britain, many of our archaeologists have not been so enlightened, and this is mainly due to the apparent conflict between dendrochronology and the desire to preserve the timbers of unique structures. Because conservation is considered to be more important, extensive sampling for treering analysis is not being carried out, thus depriving British archaeology of the sort of results which are being obtained on the Continent. At some of our major excavations, vital structural timbers are in storage awaiting conservation, while the smaller, less suitable, piles and stakes, often related to peripheral features, are sampled for tree-ring analysis. As a result, few tree-ring dates have been obtained. This conflict between dendrochronology and conservation need not occur-the two can be combined, and many samples examined in the Sheffield laboratory have subsequently been returned for conservation. This matter is referred to below, and the value of both tree-ring analyses and conservation of artifacts for certain archaeological projects will not need stressing.

\section{IS CONSERVATION ALWAYS NECESSARY?}

The first priority is to decide whether conservation is really required. There has been a tendency recently to conserve large quantities of structural timbers. For some of these, detailed drawings and photographs would be just as adequate and would save much valuable storage space as well as the conservator's time. Alternatively, replicas can be made for display purposes, leaving the original timbers free for tree-ring dating and other postexcavation work. This has been done at the National Maritime Museum, where fibreglass replicas of the Ferriby and Graveney boats are now on display.

However, there are cases for large scale conservation for the purpose of reconstructions and for future studies using techniques which have yet to be devised. This applies particularly to prehistoric timber which survives in rare circumstances (e.g. PLS. XV, XVII). If conservation is deemed necessary, there are several alternatives. On some sites, such as Runnymede (Longley \& Needham, 1979), timbers are sufficiently abundant to allow a proportion to be sampled for dendrochronology, leaving the remainder for conservation if required. The advantage here was that all the timbers were roundwood piles, i.e. similar in shape and function. So there was no clash of interest. Other timbers may be large enough, or perhaps damaged at one end, for a section to be removed from an unimportant and featureless area which would in any case be discarded. Difficulty arises when entire timbers are wanted for conservation and the eventual reconstruction of a feature, such as a house, boat or trackway. As outlined below, this need not exclude tree-ring analysis; only wooden objects such as statues might be so small and precious that sampling could not be considered.

\section{SAMPLING FOR TREE-RING ANALYSIS}

A number of recording techniques can ensure that the appearance of the timber is not altered after sampling and replacement of the section. Thorough photographic records and detailed drawings may be supplemented by the production of plaster casts for the more precious objects; photogrammetry is also useful prior to sampling.

In the case of oak, sampling should, if possible, be carried out across the widest part of the timber where the wood is sound and not too dried out. This may mean a central part of the beam and thus involve two cuts. Any apparent sapwood must be included, although its presence is not easy to determine on the surface (it is more likely to survive on a corner, and may be paler in colour and insect-attacked). Sectioning across sapwood at the widest point of the timber ensures that the maximum number of growth rings are measured and that an accurate estimate of the felling date of the tree may be calculated. The slice of timber should be 5-10 $\mathrm{cm}$. thick; samples thicker than this cannot be accommodated under the microscope and present greater difficulties in analysis, but can be accepted if conservation demands the minimum possible damage. The slice needs to be substantial enough to withstand breakage since broken samples may lead to unrecorded rings and thus to inaccuracies. If the timber is already split, or looks likely to, and the surface needs protecting, wrapping of bandages on either side of the cut will hold the wood firmly in place. Many substantial oak timbers will require a chain-saw, while softer material responds to a cross-cut saw. Gentle 
handling and care can be achieved to ensure the minimum of damage. Related edges of the wood may be marked with coloured pins, or something similar, to allow for the correct replacement of the slice into the timber. The cut section must be kept under the same conditions as the original, whether waterlogged or dry.

A frequent question concerns the possibility of removing a core from the timber, which would appear at first sight to be less destructive. However, hand-driven increment borers are not strong enough to penetrate very hard waterlogged oak, and would merely crush soft material. A power-driven borer might be suitable for hard wood but few have been developed as yet. In addition, several samples would probably have to be taken since the direction of the growth rings within the beam is unknown. The small size of a core does not allow for the 'chasing' of difficult narrow or distorted rings around the circumference. Hence the use of cores has not been developed in Britain to any extent, except in the study of timber-framed buildings.

In the dendrochronological laboratory, the wood sample is deep-frozen (only the most degraded of wood suffers from this by radial cracking), and the surface is either planed (all over the transverse surface) or cut with a sharp knife (along one edge or radius) to expose the growth rings clearly. This process removes only a minute amount of wood, perhaps a millimetre or so. Alternatively, if the timber has dried out it can be sanded. After preparation, the section is placed under the microscope for ring-width measurement; immediately afterwards it is returned to its packaging, ready for replacement in the original timber (PL. XVIIIa).

\section{TREE-RING ANALYSIS AFTER CONSERVATION}

Several timbers already in the process of conservation have been examined in the tree-ring laboratory; some from the Somerset Levels trackways (Coles, I975-80) had been immersed in carbowax (PEG 4000) for a short time, and the presence of the wax did not allow thorough freezing to take place. As a result the softer wood was difficult to surface satisfactorily. At a more advanced stage of carbowax treatment, the wax can so block the earlywood vessels as to make them indistinguishable. It should be noted that the Somerset Levels wood is immersed in PEG for about 9 months and is heated to a temperature of around $55^{\circ} \mathrm{C}$, so that it becomes extremely soft and fragile in the tanks and is heavily impregnated with carbowax; upon with- drawal from the tanks, the hardening of the wax makes it difficult for the wood to be considered suitable for tree-ring analysis afterwards. However, more recent and less degraded timber which has completed the conservation process in PEG has proved to be perfectly suitable for surfacing with a sharp knife and hence for ring-width measurement.

Wooden artifacts which have been stored in museums for a long time have often been treated in some way, e.g. Ferriby boats $I$ and 2 (Wright, 1976), the timbers of which were soaked in glycerine; boat 2 was then treated with araldite. (A replica on display in the National Maritime Museum enabled the Ferriby timbers to be sampled for tree-ring analysis.) Given a certain amount of experimentation and patience, they can often be surfaced and analysed. Air abrasion may be a useful surfacing method in such circumstances; it was used successfully for recent in situ tree-ring analysis of the timber of St Cuthbert's coffin in Durham Cathedral (Hillam, I978 unpubl.). Pressurized air cleared the vessels and made the rings visible without darnaging the wood. Naturally dried museum pieces such as logboats (= dugout canoes) and coffins may not be suitable for examination owing to their brittle texture and the impossibility of sawing out a section.

Tree-ring work on conserved timber has not been extensive and is still at a research stage, using whatever methods are found to be appropriate at the time. So it is impossible to predict whether analysis can be done on a particular piece; experience up to now suggests that success can usually be achieved and that the attempt is well worth while.

HOW THE PROBLEM IS RESOLVED IN THE SOMERSET L.EVELS

The great quantity of timber and roundwood employed in the Somerset Levels trackways and platforms (Coles, 1975-80; Coles \& Orme, 1980) allows extensive sampling for tree-ring analyses to take place. Often the abundance of wood enables both the 'pure' conservation school and the treering analysts to select objects without physical division of any individual pieces. However, and this is surely the point of the argument, on many occasions the large and well-worked timbers of the Neolithic or Bronze Age are just those required for both conservation and for tree-ring analysis (e.g. PL. XVI). Planks of oak, ash and lime, posts and 
pegs of split timber or of large-diameter roundwood, are not that common on British prehistoric sites to be readily assigned solely for one or other of the competing studies, and for some time now it has been the practice in the Levels to cater for both interests. The wood, while still in situ, is marked with both red and black pins, the former signifying to the excavators that the piece is destined for tree-ring study, the latter denoting that partial or complete conservation is to be attempted. In either case, the pins signal that the wood is not to be allowed to deteriorate by exposure or handling.

Following the recording of these pieces, they are removed as soon as possible from the peats, watered and bandaged or cushioned for the journey by van to the conservation laboratory in the Levels. Within a relatively few minutes, not hours, the pieces are unwrapped, cleaned by paintbrush and fresh water, measured and recorded, photographed and immersed in tanks of clean water. Here they remain until decisions can be taken about the precise requirements of tree-ring analysts and conservators, with the advantage of a full assemblage at the laboratory of all the likely pieces from the site or sites.

During the selection process, certain pieces of wood are often seen to be closely matched in general appearance to others which are in better condition, uncracked, firm or undamaged. These less-thanperfect specimens are often entirely suitable in parts for tree-ring sampling, and so they can be sliced or sawn for specialist work. Some pieces may have parts admirably suited for the demonstration of prehistoric woodland technology, and other parts adequate for sampling; these are divided up into the respective segments.

Finally, the timber and roundwood that is immaculate and required for complete conservation, as well as for tree-ring analyses, is chosen. On roundwood of various species, most of the woodworking traces will tend to be at the extremities, of pegs for example, and in these cases it is easy to cut out a segment, a pie slice from the centre section, or perhaps to remove the unworked end of the stem or branch. The piece is then packed for transport to the tree-ring laboratory where it is speedily prepared, measured and re-packed for transmission back to the conservation centre; this operation is completed within a very few days. The segment is inserted back into or onto the complete piece, pinned if necessary and/or bandaged, and the conservation process then proceeds as usual. As very small pieces have a greater tendency to twist or shrink in the process than do very large pieces of roundwood, it is considered necessary to put the fragment back in place before the PEG process starts. The results of the pieces so far handled in this way show no alteration from the original, the PEG upon solidification providing sufficient adhesion to grip the small fragment and hold it in place.

If the prehistoric artifact to be both sampled and conserved is timber, i.e. a plank, a board or a stake made from a plank, then a different procedure is followed. The analyst selects the most appropriate position for the tree-ring section, and the piece is then sawn entirely in two. The smaller piece is removed for preparation and measuring, in the usual way, then returned to the laboratory. A 'smaller piece' may be $0.5 \mathrm{~m}$ long and quite thick as befits a heavy pile or substantial plank, and experience with timber suggests that it is easier to conserve the parent and the smaller pieces separately; it would be difficult to hold them securely together in the PEG tank. The problems with PEG penetration of oak are well-known, and it is essential to ensure that no differential shrinkage or twisting occurs, or else the piece is spoiled for future study or display. The dimensions of timber handled in the Project's laboratory do not exceed $1.5 \mathrm{~m}$ long, $0.4 \mathrm{~m}$ wide, by $0.3 \mathrm{~m}$ thick, and it is now possible to achieve regular and uniform results by an adjustment of the normal heating maximum in the final stages of the process (see Coles 198I for the current procedure). This has allowed perfect fits between two pieces of timber sampled for treering or other analysis before conservation. The value of both approaches need not be emphasized here, and the problems of interrupting the conservation process, noted above, need never arise again.

\section{CONCLUSION}

The examination of timbers requiring conservation has now been done on sufficient material, (e.g. in the Somerset Levels (Morgan, 1979, 65; 1980, 71) and the prehistoric Brigg boat (Hillam, 1980)PL. XVII) to prove that it does work, and the results have easily repaid the extra effort involved. Since, in these cases, the timbers were from the prehistoric period, no absolute dating resulted from the dendrochronological analysis as no reference chronologies extend so far back in time. However, 
other information can be extracted from the timbers about their use and origins. This should be considered when deciding whether or not to sample for tree-ring analysis: as well as providing absolute or relative dating, it can show for example how many trees were used in each structure, their size, age and how they were converted, and also give a certain amount of detail on the original woodland structure. Again, however, maximum sampling is needed to ensure the reliability of such detailed evidence (Hillam \& Morgan, I980).

It is urged that archaeologists reconsider this matter of dendrochronology and conservation. The question is arising regularly on waterlogged sites where the best preserved and finest quality timbers for conservation (such as wide radial boards) are also those most suitable for dendrochronology and likely to provide the most accurate results in dating. Is it more important to have a complete timber, perhaps already damaged by prolonged burial and exposure to air, at the expense of accurate dating and other information? Or at the expense of constructing long tree-ring chronologies which might be useful for dating future sites? Any slight damage which should occur in sampling is surely unimportant in such cases. It is vital that preservation and display take second place to tree-ring analysis where this is thought to be feasible, on the more substantial oak timbers of some of our unique archaeological structures.

\section{BIBLIOGRAPHY}

BAILliE, M. G. L. 1977. Dublin medieval chronology, Tree-Ring Bulletin 37, 13-20.

COLES, J. M. (ed.). I975-1980. Somerset Levels Papers, I-6

1981. Conservation of wooden artefacts from the Somerset Levels: 3, Somerset luevels Papers, 7, 70-8. COLES, J. M. \& B. J. ORME. 1980. Prehistory of the Somerset Levels

ECKSTEIN, D. I978. Dating of the medieval settlement of Haithabu (Hedeby), in (ed.) J. M. Fletcher, Dendrochronology in Europe, BAR $\mathrm{S}_{51}, 267-74$.

1980. The medieval waterfront of Schleswig, North Germany, in (eds) G. Milne \& B. Hobley, Waterfront archaeology in North European towns, CBA Research Report, forthcoming.

ECKSTEIN, D., W. A. VAN ES \& E. HOLLSTEIN. 1975. Beitrag zu Datierung der frühmittelalterlichen Siedlung Dorestad, Holland, Berichten van de Rijksdienst voor het oudheid kundig Bodemoderzoek, 25, 165-75.

HILlAM, J. 1978 (unpubl.). Dendrochronology of St Cuthbert's coffin, DoE dendrochronology report.

1980. Tree-ring analysis of the Brigg 'raft' timbers, in (ed.) S. McGrail, The Brigg 'raft' and her prehistoric environment (BAR/NMM) forthcoming 1981 .
HILLAM, J. \& R. A. MORGAN. I980. What value dendrochronology to waterfront archaeology?, in (eds.) G. Milne \& B. Hobley, Waterfront archaeology in North European towns, CBA Research Report, forthcorning.

HOLLSTEIN, E. I965. Jahrringchronologische Datierung von Eichenhölzern ohne Waldkante, Bonner fahrbuch, $165,12-27$.

HUBER, B. \&. v. GIERTz. I970. Central European dendrochronology for the Middle Ages, in (ed.) R. Berger, Scientific methods in medieval archaeology, 201-12.

LAWLER, E. I980. The photography of waterlogged wood, Archaeolog, I3, 3-5 (Royal Photographic Society).

LONGLEY, D. \&. S. NEEDHAM. 1979. Egham: a bronze age settlement and waterfront, Curr. Archaeol., 6, 262-7.

MORGAN, R. A. I979. Tree-ring studies in the Somerset Levels: the Drove site of the Sweet track, Somerset Levels Papers 5, 65-75.

1980. Tree-ring studies in the Somerset Levels: Tinney's Ground, Somerset Levels Papers, 6, 69-72. wRIGHT, E. v. 1976. The North Ferriby boats, NMM Maritime Monograph and report 23.

\section{ADVERTISE in ANTIQUITY}

$\begin{array}{ll}\text { Space } & \text { Rate } \\ \text { 1 page } & £ 125 \\ \frac{1}{2} \text { page } & £ 80 \\ \frac{1}{4} \text { page } & f 50 \\ \text { Insert } & f 80\end{array}$

\section{Type Area}

$7 \frac{7}{8} " \times 5 \frac{7}{8} "(200 \times 149 \mathrm{~mm})$

$3 \frac{7 \bar{B}^{\prime \prime}}{} \times 5 \frac{77^{\prime \prime}}{}$ or $7 \frac{7{ }^{\prime \prime}}{8} \times 2 \frac{13 \prime \prime}{16}(98 \times 149 \mathrm{~mm}$ or $200 \times 71 \mathrm{~mm})$

$3 \frac{7 "}{8} \times 2 \frac{13 \prime \prime}{16}(98 \times 71 \mathrm{mrn})$

Maximum size $8 \frac{3}{4} " \times 63^{\prime \prime}(222 \times 171 \mathrm{~mm})$

No folders : single sheets only 


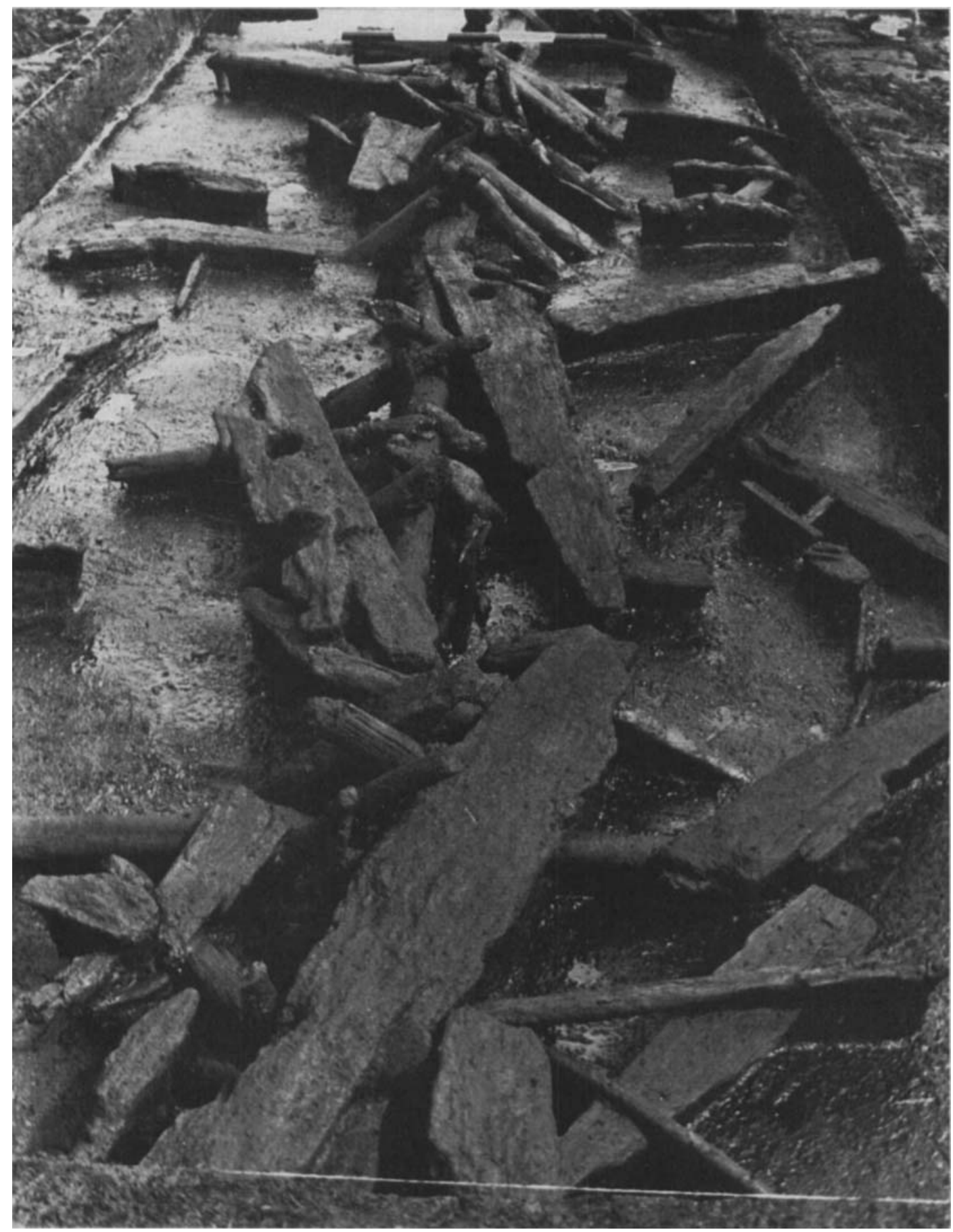

PLATE XV: TREE-RING SAMPLING AND CONSERVATION

The Sweet track, Somerset Levels. A neolithic walkway of oak boards (mostly now dislodged) based on a rail, post and peg substructure. The roundwood and timber have provided many tree-ring samples as well as being extensively conserved-quantities enable both to be carried out without too much conflict on this unique structure 


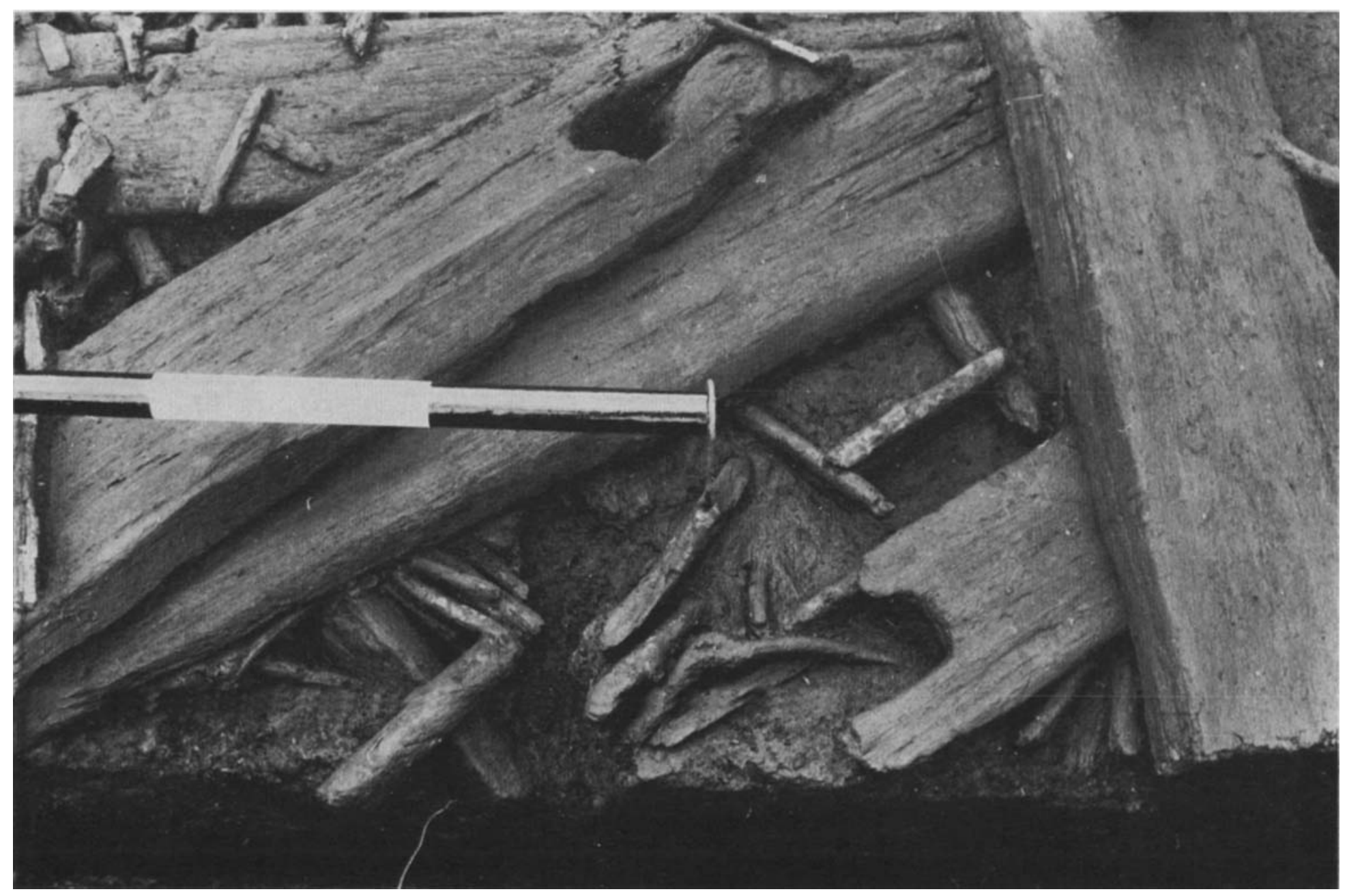

PLATE XVI: TREE-RING SAMPLING AND CONSERVATION

Some of the very well-preserved oak boards of the Meare Heath track in the Somerset Levels, a late bronze age structure. Almost total tree-ring sampling is providing invaluable detailed information, while many of the pieces are subsequently returned for conservation See pp. 90-5 


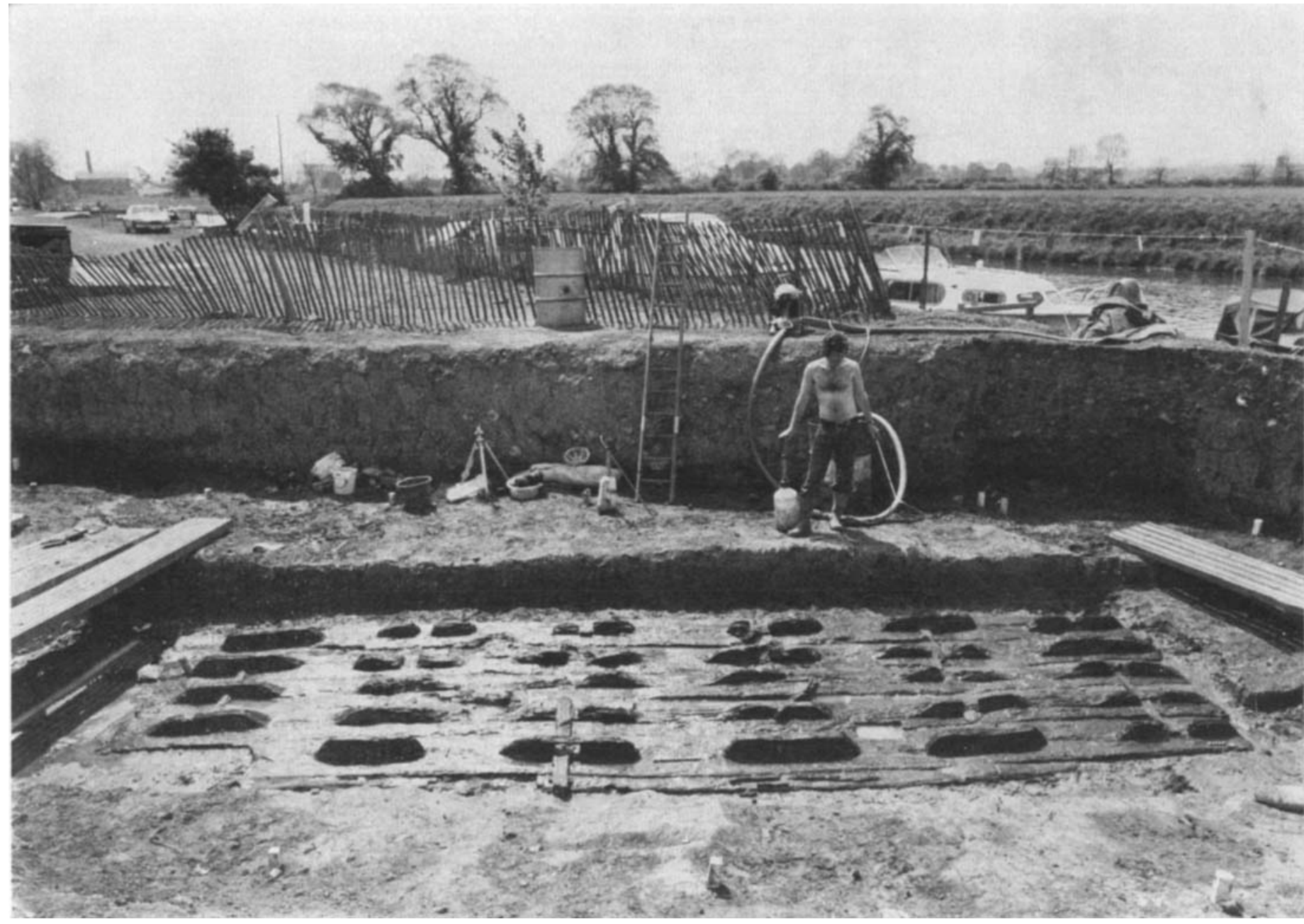

PLATE XVII: TREE-RING SAMPLING AND CONSERVATION

General view of the Brigg 'raft', the remains of an iron age boat found in South Humberside. A tree-ring sample was remozed See pp. 90-5 from each of the planks prior to conservation 


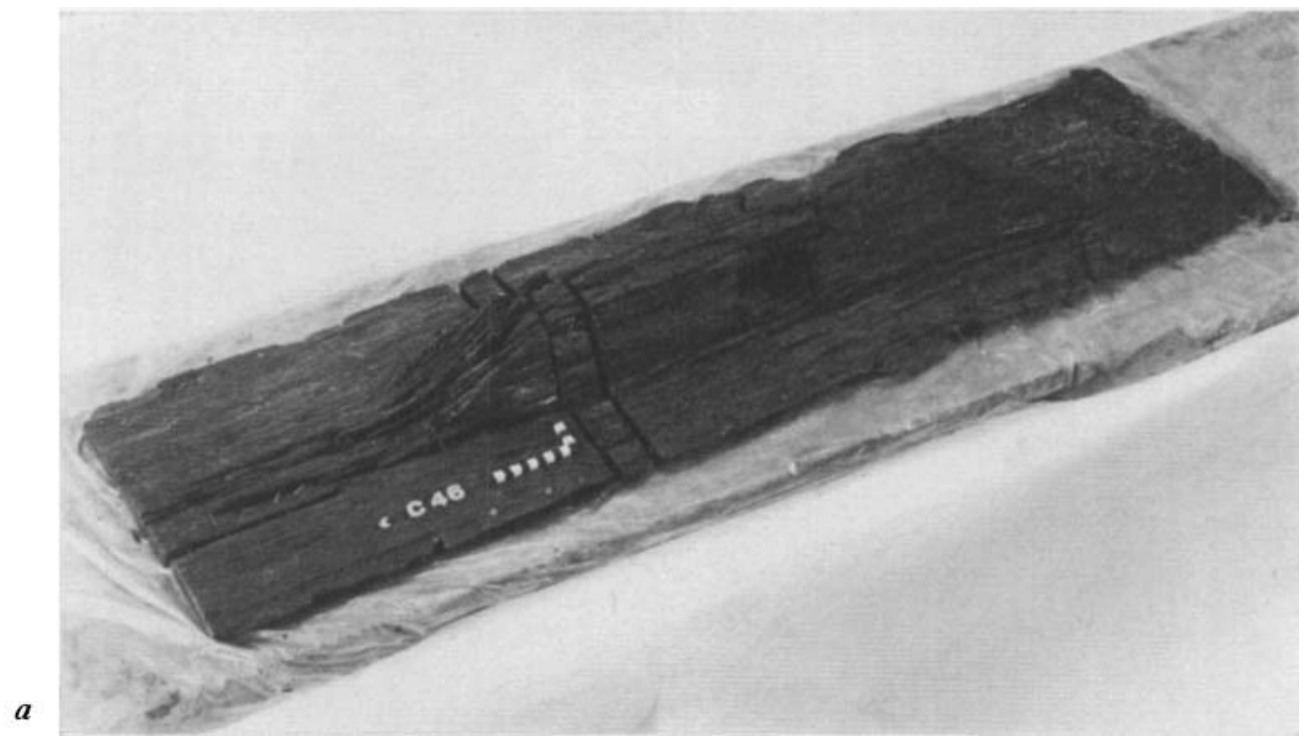

Plate XVIII $a$ : TREE-RING SAMPLing AND CONSERVATion: Cleat 4 , part of the fourth plank of the Brigg 'raft' has been replaced and is now ready to be rejoined. The sections have been opened out for clarity of photography

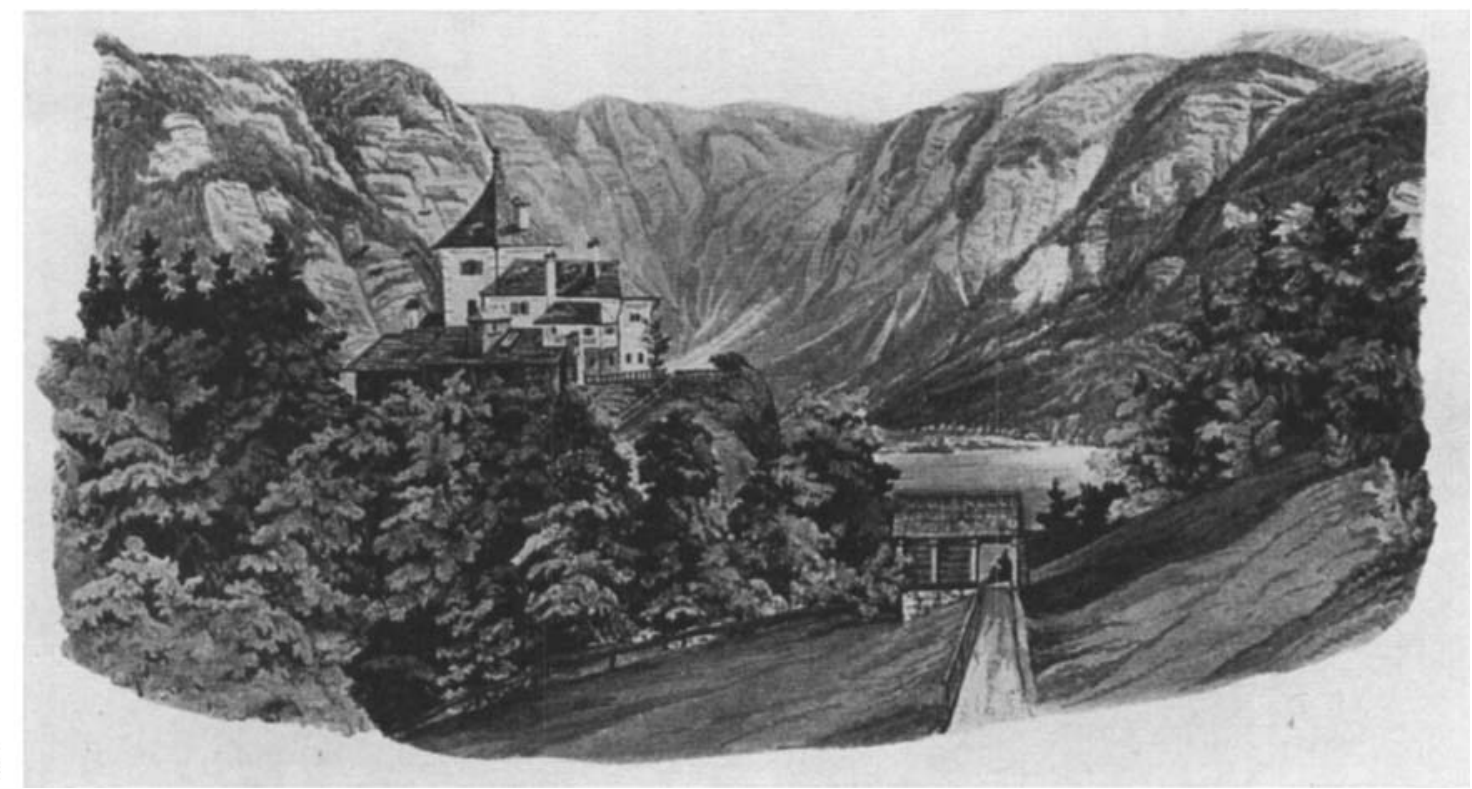

PLATE XVII $b$ : кELTi коммт! : Hallstatt. Watercolour showing the Rudolfsturm and Celtic cemetery area from the Vienna copy of the 'Grabungsprotokoll', compiled I846-63 by $\mathcal{F}$. G Ramsauer 